\title{
Mechanical Thrombectomy in Post-Transplant Heart
}

\author{
Puneeth Shridhar1, Ramzi Khalil'², Triston Smith ${ }^{3}$, Gustav Eles², David Lasorda ${ }^{2}$, Young Jae Chun ${ }^{1,4,5}$ \\ ${ }^{1}$ Department of Bioengineering, University of Pittsburgh, Pittsburgh, USA \\ ${ }^{2}$ Department of Cardiology, Allegheny General Hospital, Pittsburgh, USA \\ ${ }^{3}$ Department of Cardiology, Wheeling Hospital, Wheeling, USA \\ ${ }^{4}$ Department of Industrial Engineering, University of Pittsburgh, Pittsburgh, USA \\ ${ }^{5} \mathrm{McGowan}$ Institute for Regenerative Medicine, Pittsburgh, USA \\ Email: pus8@pitt.edu,yjchun@pitt.edu,dlasorda@wpahs.org
}

How to cite this paper: Shridhar, P., Khalil, R., Smith, T., Eles, G., Lasorda, D. and Chun, Y.J. (2016) Mechanical Thrombectomy in Post-Transplant Heart. World Journal or Cardiovascular Diseases, 6, 338-341. http://dx.doi.org/10.4236/wicd.2016.610039

Received: August 6, 2016

Accepted: October 7, 2016

Published: October 10, 2016

Copyright $\odot 2016$ by authors and Scientific Research Publishing Inc. This work is licensed under the Creative Commons Attribution International License (CC BY 4.0).

http://creativecommons.org/licenses/by/4.0/

\begin{abstract}
Coronary allograft vasculopathy (CAV) is an accelerated form of coronary artery disease that is responsible for significant mortality after cardiac transplantation. We report a case of CAV with significant thrombus burden which was managed with mechanical thrombectomy. Both aspiration and mechanical thrombectomy can be safely done in cardiac transplant recipients and may be considered in order to minimize exposure to coronary artery bypass procedure. This is especially valuable in emergency circumstances.
\end{abstract}

\section{Keywords}

Cardiac Transplantation, Heart Transplantation, Coronary Allograft Vasculopathy

\section{Introduction}

Coronary allograft vasculopathy (CAV) is leading cause of graft failure in both adult and pediatric cardiac transplant recipients [1] [2]. Coronary angiography is usually the standard procedure utilized in the screening for CAV. However, the experience with use of thrombectomy devices in these cases is limited.

\section{Case Report}

A 68-year-old man who underwent orthotropic heart transplantation was transferred to the critical care service after complaints of typical chest pain radiating to the left arm. He had a previous history of ischemic cardiomyopathy managed by left ventricular assist device placement. The donor was an intravenous drug abuser in the past with no 
history of coronary artery disease. Although donor was found nucleic acid amplification test negative, no episode allograft rejection was observed. On post-transplant coronary angiography, cardiac index of $2.68 \mathrm{l} / \mathrm{min} / \mathrm{m}^{2}$ with elevated wedge pressure and severe pulmonary hypertension were noted. On physical examination, blood pressure was noted as $111 / 61 \mathrm{mmHg}$, and an irregular heart rate of 102 beats/min. ST-segment changes on standard electrocardiogram (EKG) were consistent with acute myocardial infarction. The patient went into ventricular fibrillation. He was coded and ventilated. After receiving aspirin, heparin, phenylephrine, nor-adrenaline and high dose epinephrine, the patient was urgently referred to the catheter laboratory. Coronary angiography revealed thrombotic occlusion of the left main (LM) artery and proximal to mid portion of left anterior descending (LAD) artery (Figure 1).

After unsuccessful aspiration thrombectomy, three rounds of mechanical thrombectomy with Angiojet Catheter (Figure 2). The lesions of the left main and proximal LAD were dilated with $2.5 \times 12 \mathrm{~mm}$ balloon. It was noted the patient still has eccentric residual thrombus in the proximal-mid LAD with TIMI-3 flow distally (Figure 3 ).

Inotropic support, intra-aortic balloon pumping and assisted mechanical ventilation were necessary over the following days to normalize circulatory function. There was significant improvement in symptoms and the patient was discharged without any complications.

\section{Discussion}

This is a case of thrombotic coronary allograft vasculopathy in a post heart transplant patient. Successful manual thrombectomy has been previously described in a heart transplant patient [2]. Direct comparison of outcomes in patients treated with coronary artery bypass surgery $(\mathrm{CABG})$ vs. percutaneous coronary intervention (PCI) is not possible from our data.



Figure 1. Coronary angiography depicting thrombus occlusion of left main artery and proximalto-mid portion of left anterior descending artery. 




Figure 2. Coronary angiography after three rounds of mechanical thrombectomy.



Figure 3. Coronary angiography showing distal TIMI 3 flow with eccentric residual thrombus.

However, based on historical reports, CABG carries a very high mortality in these patients [3] [4]. In view of heavy thrombus burden, we decided to perform mechanical thrombectomy with partial success. However, the long term results of mechanical thrombectomy in this population are yet to be determined.

\section{Conclusion}

Mechanical thrombectomy could be safely used in post-transplant heart in case aspiration thrombectomy fails to clear the thrombus burden.

\section{References}

[1] Peter, S., Hulme, O., Deuse, T., Vrtovec, B., Fearon, W.F., Hunt, S., et al. (2013) ST-Elevation Myocardial Infarction Following Heart Transplantation as an Unusual Presentation of 
Coronary Allograft Vasculopathy: A Case Report. Transplantation Proceedings, 45, 787791. http://dx.doi.org/10.1016/j.transproceed.2012.08.021

[2] Colombo, P., Bruschi, G., Agozzino, M., Silva, P., Frigerio, M., Vitali, E., Arbustini, E., et al. (2008) Thromboaspiration during Acute Myocardial Infarction in a Heart Transplant Patient. Journal of Cardiovascular Medicine, 9, 293-295.

http://dx.doi.org/10.2459/JCM.0b013e328216240a

[3] Alam, M., Shahzad, S.A., Akhtar, A., Huang, H.D., Rogers, P.A., Ramanathan, K.B., et al. (2012) Long-Term Clinical Outcomes after Percutaneous Coronary Intervention for Unprotected Left Main Coronary Artery in Heart Transplant Patients with Cardiac Allograft Vasculopathy. International Journal of Cardiology, 156, 101-104.

http://dx.doi.org/10.1016/j.ijcard.2011.12.115

[4] Hayes, D., Schell, R.M., Plunkett, M.D., Gurley, J.C. and Hoopes, C.W. (2012) AngioJet Rheolytic Thrombectomy for Thrombotic Myocardial Injury in a 15-Year-Old Cystic Fibrosis Patient during Lung Transplantation. The Annals of Thoracic Surgery, 94, 626-628. http://dx.doi.org/10.1016/j.athoracsur.2011.12.086

\section{Abbreviations}

$\mathrm{CAV}=$ Coronary Allograft Vasculopathy,

$\mathrm{EKG}=$ Electrocardiogram,

$\mathrm{LM}=$ Left Main,

$\mathrm{LAD}=$ Left Anterior Descending,

STEMI = ST-Elevation Myocardial Infarction,

TIMI $=$ Thrombolysis in Myocardial Infarction,

$\mathrm{CABG}=$ Coronary Artery Bypass Surgery,

$\mathrm{PCI}=$ Percutaneous Coronary Intervention.

Submit or recommend next manuscript to SCIRP and we will provide best service for you:

Accepting pre-submission inquiries through Email, Facebook, LinkedIn, Twitter, etc.

A wide selection of journals (inclusive of 9 subjects, more than 200 journals)

Providing 24-hour high-quality service

User-friendly online submission system

Fair and swift peer-review system

Efficient typesetting and proofreading procedure

Display of the result of downloads and visits, as well as the number of cited articles

Maximum dissemination of your research work

Submit your manuscript at: http://papersubmission.scirp.org/

Or contactwjcd@scirp.org 